\title{
On a generalized magnitude system in the brain: an integrative perspective
}

\section{Carmelo M. Vicario*}

School of Psychology, The University of Queensland, Brisbane, QLD, Australia

*Correspondence: carmelo.vicario@uniroma1.it

\section{Edited by:}

Lorenza S. Colzato, Leiden University, Netherlands

Keywords: time, space, numbers, perception, cognition

Research in the field of cognitive neuroscience has provided extensive evidence in support of a strong relationship between time, space, and number in the human brain. In 1993, Dehaene et al. discovered the SNARC (spatial-numerical association of response codes) effect and suggested that numbers may be internally represented along a spatial dimension, with low numbers on the left of a mental number line, and high numbers on the right. The investigation of this effect has been studied through the use of different methodologies and recent insights have extent this effect also to decisional processes (Daar and Pratt, 2008; Loetscher et al., 2008; Vicario, 2012, 2013).

Similar relationships were also documented in research investigating link between space and time (DeLong, 1981; Vicario et al., 2007, 2009, 2011a,b; Ishihara et al., 2008; Vallesi et al., 2008; Fabbri et al., 2013) as well as between time and numbers (for instance see Dormal et al., 2006; Vicario et al., 2008; Lu et al., 2009; Vicario, 2011).

This literature corroborates the suggestion of common cortical metrics for space time and numbers (Walsh, 2003). However, despite the 10 years that have elapsed since Walsh (2003) published his theoretical work, the debate about "A theory of Magnitude" (ATOM) is still object of discussion.

This research topic entitled "On a generalized magnitude system in the brain: insights from experimental evidence" contains 10 state-of-the-art original research articles exploring the relationships between time, space and number. These research articles provide original contributions about the representation of magnitude in different research fields including childhood participants (Bottini and Casasanto, 2013; Lonnemann et al., 2013; Tokita and Ishiguchi, 2013), genetic polymorphism (Júlio-Costa et al., 2013), clinical populations such as schizophrenia (MartinezCascales et al., 2013) and right brain damaged patients (Ishihara et al., 2013), investigations on healthy adults (Baker et al., 2013; Blini et al., 2013; Crollen et al., 2013; Viarouge and de Hevia, 2013).

A lively contribute to this debate is also provided by the mini-review of Leibovich and Henik (2013) and six opinion articles (Agrillo and Miletto Petrazzini, 2013; Arzy et al., 2013; De Simone, 2013; Tzelgov et al., 2013; Van Opstal and Verguts, 2013; Vicario et al., 2013). These theoretical contributions address ATOM from different perspectives, revealing the strengths but also the weaknesses of this model.

Much more work needs to be done and many issues remain to be addressed before we fully understand the brain mechanisms underlying the existence of analogies (Vicario and Martino, 2010) between magnitudes.
It has been a great pleasure and honor to be involved in this Research Topic. I would like to thank all of the authors, reviewers, and Frontiers staff for helping to make this Research Topic possible and I look forward to further explorations of the brain mechanisms underlying ATOM.

\section{REFERENCES}

Agrillo, C., and Miletto Petrazzini, M. E. (2013). Glimpse of ATOM in non-human species. Front. Psychol. 4:460. doi: 10.3389/fpsyg.2013.00460

Arzy, S. (2013). When speaking of the experience, do not leave out the experiencer: on self and magnitude. Front. Psychol. 4:303. doi: 10.3389/fpsyg.2013.00303

Baker, J. M., Rodzon, K. S., and Jordan, K. (2013). The impact of emotion on numerosity estimation. Front. Psychol. 4:521. doi: 10.3389/fpsyg.2013.00521

Blini, E., Cattaneo, Z., and Vallar, G. (2013). Different effects of numerical magnitude on visual and proprioceptive reference frames. Front. Psychol. 4:190. doi: 10.3389/fpsyg.2013.00190

Bottini, R., and Casasanto, D. (2013). Space and time in the child's mind: metaphoric or ATOMic? Front. Psychol. 4:803. doi: 10.3389/fpsyg.2013.00803

Crollen, V., Grade, S., Pesenti, M., and Dormal, V. (2013). A common metric magnitude system for the perception and production of numerosity, length, and duration. Front. Psychol. 4:449. doi: 10.3389/fpsyg.2013.00449

Daar, M., and Pratt, J. (2008). Digits affect actions: the SNARC effect and response selection. Cortex. 44, 400-405. doi: 10.1016/j.cortex.2007.12.003

Dehaene, S., Bossini, S., and Giraux, P. (1993). The mental representation of parity and numerical magnitude. J. Exp. Psychol. Gen. 122, 371-396.

DeLong, A. J. (1981). Phenomenological space-time: toward an experiential relativity. Science 213, 681-683. doi: 10.1126/science.7256273

De Simone, L. (2013). Grounding magnitudes. Front. Psychol. 4:410. doi: 10.3389/ fpsyg.2013.00410

Dormal, V., Seron, X., and Pesenti, M. (2006). Numerosity-duration interference: a stroop experiment. Acta Psychol. 121, 109-124. doi: 10.1016/j.actpsy. 2005.06.003

Fabbri, M., Cellini, N., Martoni, M., Tonetti, L., and Natale, V. (2013). Perceptual and motor congruency effects in time-space association. Atten. Percept. Psychophys. doi: 10.3758/s13414-013-0519-9. [Epub ahead of print].

Ishihara, M., Keller, P. E., Rossetti, Y., and Prinz, W. (2008). Horizontal spatial representations of time: evidence for the STEARC effect. Cortex 44, 454-461. doi: 10.1016/j.cortex.2007.08.010

Ishihara, M., Revol, P., Jacquin-Courtois, S., Mayet, R., Rode, G., Boisson, D., et al. (2013). Tonal cues modulate line bisection performance: preliminary evidence for a new rehabilitation prospect. Front. Psychol. 4:704. doi: 10.3389/fpsyg.2013.00704

Júlio-Costa, A., Antunes, A. M., Lopes-Silva, J. B., Moreira, B. C., Vianna, G. S., Wood, G., et al. (2013). Count on dopamine: influences of COMT polymorphisms on numerical cognition. Front. Psychol. 4:531. doi: 10.3389/fpsyg.2013.00531

Leibovich, T., and Henik, A. (2013). Magnitude processing in non-symbolic stimuli. Front. Psychol. 4:375. doi: 10.3389/fpsyg.2013.00375

Loetscher, T., Schwarz, U., Schubiger, M., and Brugger, P. (2008). Head turns bias the brain's internal random generator. Curr. Biol. 18, R60-R62. doi: 10.1016/j.cub.2007.11.015

Lonnemann, J., Linkersdörfer, J., Nagler, T., Hasselhorn, M., and Lindberg, S. (2013). Spatial representations of numbers and letters in children. Front. Psychol. 4:544. doi: 10.3389/fpsyg.2013.00544 
Lu, A., Hodges, B., Zhang, J., and Zhang, J. X. (2009). Contextual effects on number-time interaction. Cognition 113, 117-122. doi: 10.1016/j.cognition. 2009.07.001

Martinez-Cascales, I., De La Fuente, J., Santiago, J., and Santiago, J. (2013). Space and time bisection in schizophrenia. Front. Psychol. 4:823. doi: 10.3389/fpsyg.2013.00823

Tokita, M., and Ishiguchi, A. (2013). Effects of perceptual variables on numerosity comparison in 5-6-year-olds and adults. Front. Psychol. 4:431. doi: 10.3389/ fpsyg.2013.00431

Tzelgov, J., Zohar-Shai, B., and Nuerk, H. C. (2013). On defining quantifying and measuring the SNARC effect. Front. Psychol. 4:302. doi: 10.3389/fpsyg.2013.00302

Vallesi, A., Binns, M. A., and Shallice, T. (2008). An effect of spatial-temporal association of response codes: understanding the cognitive representations of time. Cognition 107, 501-527. doi: 10.1016/j.cognition.2007.10.011

Van Opstal, F., and Verguts, T. (2013). Is there a generalized magnitude system in the brain. Behavioral, neuroimaging, and computational evidence. Front. Psychol. 4:435. doi: 10.3389/fpsyg.2013.00435

Viarouge, A., and de Hevia, M. D. (2013). The role of numerical magnitude and order in the illusory perception of size and brightness. Front. Psychol. 4:484. doi: 10.3389/fpsyg.2013.00484

Vicario, C. M. (2011). Perceiving numbers affects the subjective temporal midpoint. Perception 40, 23-29. doi: 10.1068/p6800

Vicario, C. M. (2012). Perceiving numbers affects the internal random movements generator. Sci. World J. 2012:347068. doi: 10.1100/2012/347068

Vicario, C. M. (2013). Landmark test and decision making: a reply to a reply. Perception 42, 356-357. doi: 10.1068/p7334

Vicario, C. M., Bonní, S., and Koch, G. (2011a). Left hand dominance affects suprasecond time processing. Front. Integr. Neurosci. 5:65. doi: 10.3389/fnint.2011. 00065

Vicario, C. M., Martino, D., Pavone, E. F., and Fuggetta, G. (2011b). Lateral head turning affects temporal memory. Percept. Mot. Skills 113, 3-10. doi: 10.2466/04.22.PMS.113.4.3-10
Vicario, C. M., Caltagirone, C., and Oliveri, M. (2007). Optokinetic stimulation affects temporal estimation in healthy humans. Brain Cogn. 64, 68-73. doi: 10.1016/j.bandc.2006.12.002

Vicario, C. M., and Martino, D. (2010). The neurophysiology of magnitude: one example of extraction analogies. Cogn. Neurosci. 1, 144-145. doi: 10.1080/17588921003763969

Vicario, C. M., Pecoraro, P., Turriziani, P., Koch, G., Caltagirone, C., and Oliveri, M. (2008). Relativistic compression and expansion of experiential time in the left and right space. PLOS ONE 3:e1716. doi: 10.1371/journal.pone. 0001716

Vicario, C. M., Rappo, G., Pepi, A., and Oliveri, M. (2009). Timing flickers across sensory modalities. Perception 38, 1144-1151. doi: 10.1068/p6362

Vicario, C. M., Yates, M. J., and Nicholls, M. E. (2013). Shared deficits in space, time, and quantity processing in childhood genetic disorders. Front. Psychol. 4:43. doi: $10.3389 /$ fpsyg.2013.00043

Walsh, V. (2003). A theory of magnitude: common cortical metrics of time, space and quantity. Trends Cogn. Sci. 11, 483-488. doi: 10.1016/j.tics.2003. 09.002

Received: 16 October 2013; accepted: 18 October 2013; published online: 12 November 2013.

Citation: Vicario CM (2013) On a generalized magnitude system in the brain: an integrative perspective. Front. Psychol. 4:829. doi: 10.3389/fpsyg.2013.00829

This article was submitted to Cognition, a section of the journal Frontiers in Psychology.

Copyright (C) 2013 Vicario. This is an open-access article distributed under the terms of the Creative Commons Attribution License (CCBY). The use, distribution or reproduction in other forums is permitted, provided the original author(s) or licensor are credited and that the original publication in this journal is cited, in accordance with accepted academic practice. No use, distribution or reproduction is permitted which does not comply with these terms. 